\title{
CYCLICAL AND CAUSAL PATTERNS OF INFLATION AND GDP GROWTH
}

\author{
Mahmood Arai*, Mats Kinnwall** and Peter Skogman Thoursie ${ }^{* * *}$
}

8 February 2002

\begin{abstract}
Empirical foundations for the view that high inflation impairs GDP growth are examined using annual data for 115 countries over the period 1960-1995. Taking into account country heterogeneity and time-specific symmetric shocks, as well as endogeneity of inflation and dynamics of GDP growth we estimate dynamic panel-data models of the effects of inflation on growth. We find no evidence supporting the view that inflation is in general harmful to GDP growth. On the other hand, there is a negative correlation between contemporaneous intra-country inflation and growth for periods characterised by positive oil-price shocks.
\end{abstract}

Key words: GDP GROWTH; Inflation;

JEL Codes: E00; O11; O57

\footnotetext{
*Department of Economics, Stockholm University, SE-106 91 Stockholm, Sweden (Corresponding address) e-mail: ma@ne.su.se.

**Handelsbanken Markets, Stockholm, e-mail: maki03@handelsbanken.se.

***Department of Economics, Stockholm University and the Swedish National Social Insurance Board, e-mail: pt@ne.su.se.

This is a substantially revised version of an earlier paper by Arai and Kinnwall (1997), Macroeconomic Stability and Growth: Panel Data Analysis of Causal and Cyclical Patterns, Working Paper 97:8, Department of Economics, Stockholm University. The dynamic panel data results are new.

We wish to thank seminar participants at the Department of Economics, Stockholm University, ERMES, Université de Paris 2, the Industrial Institute for Economic and Social Research, the Swedish Institute for Social Reseach and the Riksbank for useful comments and discussions on earlier versions of this paper. We are indebted to Jan Häggström, Petter Lundvik, Henry Ohlsson and Klas-Göran Warginger for constructive suggestions on the earlier 1997 version of this paper.
} 


\section{INTRODUCTION}

The empirical literature on GDP growth and macroeconomic instability deals either with cross-section studies based on country averages over time or four to five years averages of panel data. ${ }^{1}$ Examples include studies of the relation between GDP growth and macroeconomic indicators such as inflation and the fiscal stance (e.g. Fischer (1993) and Barro (1995)). Barro reports a significantly negative correlation between inflation and GDP growth for average inflation rates above ten percent. Fischer finds a significantly negative correlation for the period after the early 1970s. Based on sensitivity analysis of cross-section regressions, Levine and Renelt (1992) found that cross-section results are unstable. This might be due to unobserved inter-country heterogeneity that is systematically correlated with explanatory variables, which leads to biased estimates even when using methods that exploit the time-series variations in the data; cf. e.g. Fischer (1993) who applied seemingly unrelated regressions.

Our purpose is to examine empirically the general relevance of two competing hypotheses. One is the "growth costs of inflation hypothesis". The second hypothesis suggests that GDP growth and inflation might be related in a non-causal manner. In particular, negative supply shocks tend to generate stagflation, that is a period of slower growth concurrently with higher inflation.

Analysing annual data for 115 countries, we find that the correlation between country averages of growth and inflation is extremely unstable, both with respect to significance and sign. A natural lesson, foreseen in previous studies, is that instead of using cross-section data or four to five years averaged panel data, one should fully exploit the richness of annual panel data and explicitly account for country heterogeneity and symmetric time-specific shocks. This is particularly important when dealing with strongly time-varying variables such as macroeconomic indicators for countries from all parts of the world over a long period of time. Available annual data on inflation and the rate of GDP growth allow for tests of causal relations, by using lagged values of the

\footnotetext{
${ }^{1}$ In the growth literature in general there are several examples of panel data analyses, see e.g. Knight, Loayza and Villaneuva (1993), Islam (1995) and Caselli et al. (1996). For a review of the growth literature see Temple (1999).
} 
regressors in a dynamic panel data model.

Available panel-data analyses in the literature all use panels of four or five-year averages. One argument is to avoid high frequency variation in variables due to the business cycle. Arbitrarily chosen, four or five-year periods do not necessarily correspond to cycles in countries that are in different phases of a cycle. The aggregation over several years might capture a cycleaverage, but might as well create variation that is purely cyclical. To deal with the problem of cyclical variation we assume a general cyclical pattern exactly as in the case of aggregated data over periods - across the sample and control for that by means of general time effects.

The second argument for using averaged data presented by Islam (1995) is to avoid serial correlation. Serial correlation leads to inconsistently estimated standard errors in a non-dynamic set-up and more seriously, inconsistent estimated coefficients in a dynamic set-up. Existence of serial correlation can be tested for, by using appropriate tests. The costs of aggregation appear in terms of i) losing information (within period variation), ii) restricting the possibility of testing the stability of estimated parameters over time, and iii) limiting the possibilities of studying the dynamic structure of the problem by using lagged variables. In order to avoid the drawbacks of averaged data, we estimate the impact of inflation on GDP growth with annual data.

Our main results are as follows. First, we detect a stable and negative contemporaneous intra-country correlation between inflation and growth for sub-periods characterised by oil price shocks. Second, examining the causal relation between inflation and GDP growth, our dynamic panel estimations on annual data do not support the hypothesis that GDP growth is in on average affected by past inflation. Our conclusion, based on these empirical results is that inflation is not generally harmful for growth.

The data are described in Section 2 and our estimation strategy is discussed in Section 3. Section 4 examines the heterogeneity of the relation between inflation and GDP growth. In Section 5 we deal with the contemporaneous correlation between inflation and growth, while Section 6 deals with causality and dynamic issues related to inflation and GDP growth. Finally, Section 7 concludes the paper. 


\section{DATA}

The original data set covers annual data for 115 countries for the period 196095. ${ }^{2}$ The data constitute an incomplete panel due to missing observations; the actual sample contains 2,874 observations. We compute annual inflation rates using data on consumer price indices. The measure of short-term inflation variability is the standard deviation of inflation for each year, based on quarterly data. Our growth measure is the annual percentage change in GDP per capita. Table A1 in Appendix contains some statistics on inflation and growth for all the countries in the sample. ${ }^{3}$ Table A2 summarises the sample statistics. In the subsequent text and tables, Sample A refers to the entire sample and Sample B denotes countries with average inflation below 200 per cent and positive growth.

There is a considerable over-time variation in inflation. Among countries with average inflation between three and four per cent (176 observations), the standard deviation of annual inflation is 3.7 per cent, while the inflation rate varies between -1.9 and 26.2 per cent. On the other hand, among countries with average inflation between six and seven per cent (312 observations), the standard deviation is 6.4 per cent, while the inflation rate varies between -1 and 24.3 per cent. Even for the sample with average inflation as high as between 21 and 22 per cent (52 observations), maximum inflation never exceeded 37 per cent. The rate of growth is also strongly time varying. In our sample, the standard deviation of growth over time varies between 0.5 to 8 times average growth.

The data cover a number of countries with negative average growth ${ }^{4}$ as well as countries with extremely high inflation. ${ }^{5}$ Most of these are African or Latin American countries that have suffered civil wars or at least internal turmoil during a substantial part of the sample period. The rate of inflation,

\footnotetext{
2 Source IFS; see IMF (1996). We excluded countries with less than three observations.

${ }^{3}$ Averages are calculated with respect to years where we record both inflation and growth.

4 These countries are Ethiopia, Ghana, Guyana, Haiti, Liberia, Madagascar, Mali, Nicaragua, Niger, Romania, Senegal, Sierra Leone, Solomon Islands, Togo and Zaire.

5 Argentina, Bolivia, Brazil, Peru, Nicaragua and Zaire all have average inflation above 200 per cent.
} 
deficits and growth in these countries might all be due to these country-specific features.

To our knowledge, all previous studies use data that are averaged over four, five or ten-year periods. Figures 1 and 2 illustrate annual variation in the data for Sample B and countries with average inflation below ten percent. Period averages neglect substantial information and limit the possibility of accounting for global time effects. Relations between macroeconomic variables and growth might be period-specific and using annual data instead of period averages allows us to examine the stability of the results over time.

The duration of cycles can vary across countries and time. Countries can be in different phase of a cycle in a given year. The aggregation over several years might capture an average over a cycle but can as well create variation that is purely cyclical. The latter can happen if the cut-off year is in the middle of a cycle that is longer that the period of aggregation. To deal with the problem of cyclical variation, we assume a general cyclical pattern across the sample and control for that by means of general time effects.

Using annual data has the following advantages: i) information on within period variation is used in estimation, ii) stability of estimated parameters over time can be tested, and iii) the dynamic structure of the problem can be thoroughly analysed by using lagged variables.

— Figure 1 and Figure 2 about here -

\section{ESTIMATION ALTERNATIVES}

We estimate the following model:

$$
\begin{aligned}
y_{i t} & =\rho y_{i t-1}+X_{i t}^{\prime} \beta+\varepsilon_{i t} ; \\
\varepsilon_{i t} & =v_{i}+v_{t}+v_{i t} \text { for } i=1,2, \ldots, N \text { and } t=1,2, \ldots, T_{i},
\end{aligned}
$$

where $y_{i t}$ and $\boldsymbol{X}_{i t}$ are vectors of dependent and explanatory variables for country $i$ in year $t$. The error term $\varepsilon_{i t}$ can be decomposed into individual effects $v_{i}$, time effects $v_{t}$, and a random term $v_{i t}$. The individual effects represent all omitted country-specific variables and the time effects represent all omitted variables 
that have symmetric effects on all countries. $\rho$ is a parameter capturing potential persistence in the growth rate (it is assumed that $|\rho|<1$ ).

Starting with the case when no persistence in the growth rate is assumed, i.e. $\rho=0$, there are several methods of estimating $\beta$. Such estimators have desired statistical properties under standard assumptions, especially given that the individual- and time effects are not correlated with the explanatory variables (see e.g. Hsiao (1986)). However, if $\mathrm{E}\left(\boldsymbol{X}_{i t} \nu_{i}\right) \neq 0$ or $\mathrm{E}\left(\boldsymbol{X}_{i t} \nu_{t}\right) \neq 0$, then a between estimator (that is, OLS on country averages) is biased. All studies that use a between estimator - common in the macro and growth literature potentially suffer from this problem when it is not statistically established that the individual and time effects are uncorrelated with explanatory variables. An alternative estimator is the within estimator that treat the individual effects as fixed over time and the time effects as fixed across individuals. This is simply OLS on transformed (centred) data $\boldsymbol{X}_{i t}-\boldsymbol{X}_{i .}-\boldsymbol{X}_{. t}-\boldsymbol{X}_{. .}$, where $\boldsymbol{X}_{i .}$ is the country average over time, $\boldsymbol{X}_{. t}$ is the average across countries in time period $t$ and $\boldsymbol{X}_{\text {.. }}$ is the global average. ${ }^{6}$ When $\mathrm{E}\left(X_{i t} v_{i}\right) \neq 0$ or $\mathrm{E}\left(X_{i t} v_{t}\right) \neq 0$, the within estimator, treating the individual effects and time effects as fixed, has all the desired statistical properties. $^{7}$

Previous studies of growth have incorporated various growth indicators in the model. Variables frequently included are initial real per capita GDP, initial school attainment, initial life expectancy, central bank independence, regional dummies, land area, index of civil rights, the ratio to GDP of government expenditure in defence or education, government consumption share, etc. Many of these variables are either time-invariant by definition or exhibit marginal time variations. It is certainly quite interesting to examine the impact of these variables on the rate of growth. However, when studying the impact on highly time-variant macroeconomic variables, it is straightforward to

\footnotetext{
${ }^{6}$ In our case, since the panel is incomplete, we use the transformation proposed by Wansbeek and Kapteyn (1989) as well as models including time dummies. It turns out that time dummies work equally well for our data. This can be due to the fact that missing observations in our data are concentrated in the 1960s and the panel is almost complete for the period after 1970.

${ }^{7}$ It should be noted that the FGLS estimator of a random effects model which is a weighted average of between and within estimators, suffers from the same problem as the between estimator when explanatory variables are correlated with the individual and time effects. Moreover, the within estimator predicts effects within the sample and is appropriate when the sample represents a considerable part of the population, as is the case for our sample.
} 
consider the individual effect, $v_{i}$, as time-invariant and control for all other country heterogeneity. This is a particularly suitable strategy in the case of annual data. The persistent level differentials in growth should most likely be due to more fundamental determinants of growth than strongly time-varying macroeconomic indicators. In this way we abstract from all level differentials in GDP growth and analyse the impact of deviations from individual levels.

Several time-varying country-specific variables are found to affect growth in the literature (see e.g. Barro \& Sala-I-Martin (1995)). Our focus is to measure the impact of inflation on growth. Omitting other variables from the empirical specification is only a problem when any of these variables is correlated with inflation. One might argue that, for example investments are positively correlated with both inflation and growth. If this is the case and contemporaneous inflation happens to be positively correlated with growth without controlling for investment, we can suspect that a great part of this obtained positive correlation reflects an underlying variation from investments. On the other hand, if no correlation between inflation and growth is found and one believes that there exists a negative relationship, it must be the case that there exists a variable that is positively related to inflation but, in contrast to inflation, enhances growth. Such a variable is difficult to find.

Besides the problem of unobserved heterogeneity potentially correlated with inflation, there are two other problems which make it difficult to obtain an accurate estimate of $\beta$. First, growth might adjust slowly to changes in other variables in the economy implying that growth might be characterised by persistence over time. In terms of the model presented above with one lagged dependent variable, $\rho$ has to be estimated in addition to $\beta$. Second, inflation and GDP growth might be simultaneously determined, suggesting that the correlation might go in both ways. In this case there will be a correlation between inflation and the pure error term i.e. $\mathrm{E}\left(\boldsymbol{X}_{i t} v_{i t}\right) \neq 0 .{ }^{8}$ To deal with these issues we estimate a dynamic panel data model applying techniques suggested by Arellano \& Bond (1991) as well as Arellano \& Bover (1995) and Blundell \& Bond (1998).

${ }^{8}$ This will also be the consequence when inflation is measured with errors. The series are continuously updated in order to increase the quality implying that measurement errors is not 
The Arellano and Bond estimation methodology involves eliminating the individual effects by transforming $v_{i}$ into first differences. The constructed correlation between the first difference of the lagged dependent variable, $\Delta y_{i t-1}$, and the first difference of the error term, $\Delta v_{i t}$, is handled by using values of the lagged dependent variable in time period $t$-2 and earlier as instruments for $\Delta y_{i t-1}$. The crucial assumption for these lagged levels to be valid instruments is absence of serial correlation in $v_{i t} \cdot{ }^{9}$ To obtain a consistent estimator of $\rho$ and $\beta$ the General Method of Moments (GMM) is applied. We denote this estimator by $\mathrm{GMM}_{\mathrm{y}}$. Absence of serial correlation in $v_{i t}$ also makes it possible to instrument inflation by its lagged values to solve a potential endogeneity problem. A variable is said to be endogenous if $\mathrm{E}\left(\boldsymbol{X}_{i t} v_{i s}\right) \neq 0$ for $t \geq s$ but $\mathrm{E}\left(\boldsymbol{X}_{i t} v_{i s}\right)=0$ for $t<s$. Thus, inflation levels in time period $t-2$ and earlier can be used as instruments for the first difference of inflation. The estimator used when both the lagged dependent variable and inflation are instrumented is denoted by $\mathrm{GMM}_{\mathrm{y}, \mathrm{x}}$.

When series are highly autoregressive and when the panel is relatively short, the Arellano \& Bond estimator has been found to perform badly, both in terms of consistency and efficiency. Arellano \& Bover (1995) and Blundell \& Bond (1998) have developed an alternative estimator that is a linear combination of the Arellano \& Bond estimator and an estimator using lagged differences as instruments for equations in levels. Lagged differences are valid instruments for levels under relatively mild assumptions. This system estimator puts larger weight to the equation in levels, the more autoregressive the series are. Since in particular inflation is highly autoregressive, we also apply the estimator suggested by Arellano \& Bover (1995) and Blundell \& Bond (1998).

likely to be a problem for the years included in this study.

9 To test the validity of this assumption we report tests for the absence of first-order and second-order serial correlation in the first differenced residuals. If the disturbances are not serially correlated, there should be evidence of significant negative first-order serial correlation in differenced residuals and no evidence of second order serial correlation in the differenced residuals. In addition, a Sargan test of over-identifying restrictions is also reported. 


\section{GDP GROWTH COSTS OF INFLATION: INTER-COUNTRY EFFECTS}

We now examine the sample heterogeneity by investigating the inter-country effects for various subsamples. For the whole sample (Sample A) a simple regression suggests a significantly negative correlation between average inflation and average growth (see Figur 3). ${ }^{10}$

— Figure 3 about here -

However, excluding Nicaragua from the sample yields an insignificant estimate for the remaining 114 countries. There is no clear pattern between inflation and GDP-growth for countries with average inflation below 200 per cent and positive growth (see Figure 4).

— Figure 4 about here -

We experiment with partitioning the data set into sub-samples. For some sub-samples we find a positive and significant correlation between average inflation and average growth. This is the case during the entire period for the OECD-countries, excluding two clear outliers, Iceland and Japan (see Figure 5) and also for the entire sample during the first half of the 1960s.

- Figure 5 about here -

The correlation between the omitted country characteristics (individual effects) and inflation might explain these results. This correlation is -0.54 for the OECD sample and 0.18 for the early 1960s in Sample A. The corresponding correlation is 0.13 for Sample A and the entire period. This indicates that all significant, negative or positive, intra-country estimates are potentially biased. It is interesting to note that the results are highly insignificant for Sample B. The correlation between individual effects and the explanatory variables is -0.07 for this sample. ${ }^{11}$ These simple exercises indicate that there is strong

${ }^{10}$ Averages in all of the figures are calculated only with respect to years where we record both inflation and growth.

${ }^{11}$ Using the Hausman-Taylor test, we cannot reject the hypothesis that this correlation is zero.

The result for this sample is highly insignificant. However, this test presumes correct 
unobserved country heterogeneity. ${ }^{12}$ To investigate this we apply within estimators to examine the effect of the inflation rate and inflation variability on growth.

\section{CONTEMPORANEOUS CORRELATION OF INFLATION AND GDP GROWTH}

Table 1 summarises our regression results for contemporaneous inflation and growth. Running a fixed effects model for the whole sample yields a negative and significant correlation between inflation in one year and growth in the same year. Controlling for time fixed-effects does not change the results substantially.

To investigate the over-time stability of the results we estimated fixed effects models using annual data for five-year periods. The time effects on an annual basis might not capture period-specific global shocks since such shocks do not influence economies simultaneously. This means that potential inflation effects might be period specific rather than year specific. Another point of this exercise is that some individual effects might, in principle, be time invariant during the entire sample period but others might change dramatically, though not on a year-to-year basis. Considering a period of five years, it can be assumed that most important growth determinants, such as institutions, human capital endowments, capital and industry structure, are usually unaltered.

Regressions for five-year periods disclose a large instability in the results. The coefficient for inflation is insignificant for the five-year periods between 1960 and 1975, regardless of whether we include the countries with extreme inflation records and negative average growth (Sample B) or not. For the whole sample and for the periods 1975-1979, 1985-1989 and 1990-1995 there is a significant negative effect. For the period 1985-1989 the negative effect does not apply to Sample B.

— Table 1 about here -

specification, which is hardly justifiable in this case.

12 The estimates for the budget deficit (not reported here) are negative and quite stable. The complete results are available from the authors on request. 
We interpret these results as implying that the statistical relation between contemporaneous inflation and growth is highly period specific. There is a robust intra-country and year negative correlation between inflation and growth for the decade after the mid-1970s and for the 1990s. While there is no significant effect for the 1960s the results for the 1980s hinge critically on the inclusion of countries with extreme inflation records and negative average growth.

The negative correlation between inflation and growth applies for periods dominated by oil price shocks. These results contradict some of the previous results reported by Fischer (1993), who rejected the hypothesis that the negative correlation during the 1970s reflects supply shocks. Fischer found an overall significantly negative correlation for the period 1960-72. This correlation, he argues, should be positive since the period was characterised by positive demand shocks. We find the same result as Fischer for the period 19601972, but when 1972 is excluded the results turn out to be far from significant. This means that Fischer's conclusion critically depends on the fact that the robustness of the results was not examined with respect to the choice of period, as well as individual and time heterogeneity.

\section{DYNAMICS AND CAUSALITY ISSUES}

The growth rate might be persistent over time, implying that lagged dependent variables should be included in the empirical growth equation. In terms of the model given in section 3 and with one lagged dependent variable as regressor we must estimate $\rho$ in addition to the $\beta$ coefficient vector. $\mathrm{GMM}_{\mathrm{y}}$ denotes the estimator when the lagged dependent variable is instrumented.

Further, there are theoretical arguments implying that causality might run in the other direction. In particular, these arguments suggest that we should expect to find a negative correlation between inflation and lagged growth, due to a money demand effect. ${ }^{13}$ To deal with this problem we also instrument the

13 Granger-causality tests on time series of inflation and GDP growth on individual countries do not provide evidence of causality of inflation on GDP growth in 84 out of 115. In 14 cases we found evidence causality: 8 negative and 6 positive. Andres \& Hernando (1997) perform Granger-causality like tests on the panel of OECD countries, under the strong assumption of a 
inflation rate by its lagged values in a similar fashion as for the lagged dependent variable. $\mathrm{GMM}_{\mathrm{X}, \mathrm{y}}$ denotes the estimator when the lagged dependent variable and inflation are instrumented with lagged values.

The results using the $\mathrm{GMM}_{\mathrm{y}}$-estimator confirm essentially the results of the within estimator presented in the previous section (see column 1, Table 2). The only significant coefficient of contemporaneous inflation for Sample A is for the seventies. In contrast to the case when the within estimator was used there are no significant effects after 1985. Regarding the Sample B there are two periods, 1970-1974, 1980-1984 and 1990-1995, with a negative and significant coefficient for inflation. ${ }^{14}$

When contemporaneous inflation is treated as endogenous the results change slightly (see column 2, Table 2). The results when using the $\mathrm{GMM}_{\mathrm{y}, \mathrm{x}^{-}}$ estimator yield significantly negative coefficients of inflation for both samples in the period 1975-1979 and also a significant coefficient for Sample A in 1990-1995. That was also the case according to the within estimator.

— Table 2 about here -

According to these results it seems to be important to consider inflation as an endogenously determined variable since there are substantial changes in the significance level for some of the periods. The main conclusion from this exercise remains, however. The correlation between contemporaneous inflation and growth is highly period specific and a negative relationship between inflation and growth seems to be driven by the oil price shocks. ${ }^{15}$ The coefficients reflecting persistence in growth (not presented in the Table 2) are in most periods insignificantly estimated using both the $\mathrm{GMM}_{\mathrm{y}^{-}}$and the $\mathrm{GMM}_{\mathrm{y}, \mathrm{x}}$-estimators. ${ }^{16}$

common dynamics of GDP growth and find mixed evidence similar to ours.

${ }^{14}$ Test statistics for AR (1) and AR (2) indicate that the residuals are not random walk and imply absence of serial correlation. This supports the hypothesis that the lagged values of growth as instruments is valid which is also confirmed by Sargan test. According to the Sargan tests we cannot reject that the instruments are uncorrelated with the errors implying validity of our instruments.

15 Tests for serial correlation in the disturbance term and the Sargan tests support the validity of the instruments also for the $\mathrm{GMM}_{\mathrm{y}, \mathrm{x}}$ estimator.

16 The results are available from the authors. Furthermore, including several lags of the growth 
It could be argued that negative growth-effects of inflation are likely to appear with a lag. In column 3 of Table 2 we present the results applying the $\mathrm{GMM}_{\mathrm{y}}$-estimator but where lagged inflation in period $t-1$ is used as regressor, which should certainly limit the problem of endogenous inflation. Above we dealt with this problem by instrumenting contemporaneous inflation. Here, we extend the analysis by instrumenting lagged inflation using the $\mathrm{GMM}_{\mathrm{y}, \mathrm{x}^{-}}$ estimator (see column 4 of Table 2). There are no negative significant coefficients of lagged inflation, using the $\mathrm{GMM}_{\mathrm{y}}$ or the $\mathrm{GMM}_{\mathrm{y}, \mathrm{x}}$-estimators. The only exception is for the period 1975-1979 and Sample B using the $\mathrm{GMM}_{\mathrm{y}, \mathrm{x}}$-estimator. ${ }^{17}$

Sensitivity analyses suggest that neither the $\mathrm{GMM}_{\mathrm{y}}$-estimator, nor the $\mathrm{GMM}_{\mathrm{y}, \mathrm{x}}$-estimator is sensitive to the number of lags used as instruments. Furthermore, if contemporaneous inflation is endogenous, lagged values of inflation might still be correlated with the error term in time period $t$. This is particularly a problem if inflation is highly autoregressive, which is certainly the case in our data. For example, if lagged inflation in period $t-2$ is correlated with the error term in time period $t-1$ it constitutes a poor instrument for the first difference of inflation. To deal with this issue we have uses lagged levels of inflation in period $t-3$ and $t-4$ as instruments to the first difference of inflation which, however, does not alter the previous results. ${ }^{18}$

Finally, lagged values are poor instruments to first differences if the series are highly autoregressive since the instrument in that case will be weakly correlated to something which is close to zero. This is a minor problem regarding the lagged dependent variable since the estimated persistence is estimated to be very small. The problem could exist for inflation since inflation is highly autoregresive for many countries. Hence, we apply a linear combination of the estimator on differences (i.e. the GMM estimator used here) and an estimator on levels using differences as instruments, proposed by

rate as regressors can also extend the empirical specification. This did not, however, contribute to the analyses.

${ }^{17}$ It should be noted that including several lags of inflation in one empirical specification does not alter the conclusions. Most of the estimated coefficients are insignificant.

18 Of course, this procedure reduces the number of observations implying that we draw conclusions from two different samples. 
Arellano \& Bover (1995) and Blundell \& Bond (1998). Briefly, the higher persistence of the series the more weight will the system estimator put on the estimator on levels implying that the poor instruments of levels for differences will be of less importance. The system estimator does no alter the previously obtained results. ${ }^{19}$

Another issue is whether high and variable inflation - not only the inflation level — is harmful for growth. A commonly used measure of inflation variability is the standard deviation of inflation. This measure is sensitive to the inflation levels and naturally highly correlated with average inflation. Without having distinguished between effects of the inflation level and variability, the conclusion in previous studies (see, for example, Fischer (1993) and Barro (1995)) has been that high and variable inflation is harmful for growth. To examine the hypothesis, we estimate models including an interaction variable between inflation and its standard deviation for each year, calculated from quarterly inflation data. The estimated coefficient for the interaction-variable is not significant, suggesting that high and volatile inflation is not generally harmful to growth.

The coefficient of variation $(C V)$, which is a level-independent measure of variability and measures relative variation, can be used to study the relation between long-term inflation variability and the rate of growth. Not surprisingly, results of correlation analyses imply that the average and $C V$ of inflation are not significantly correlated. The $C V$ of inflation for five-year periods (fixed effects model as well as regressions on country averages over the entire sample period), does not suggest a statistically significant relation between inflationvariability and the rate of growth.

\section{CONCLUSION}

Several recent empirical studies appear to suggest growth costs of macroeconomic instability. Disregarding countries with extreme records of inflation and negative 36-year average growth, we find no systematic intercountry correlation between inflation and growth.

There is a systematically negative correlation between contemporaneous

19 Results are available on request. 
inflation and growth for periods characterised by oil price shocks. It is also no surprise that high inflation and low growth are often observed in countries that have suffered civil wars or at least internal turmoil during a substantial part of the period.

Results of our dynamic panel data analysis, taking into consideration the endogeneity of inflation and dynamics of GDP growth, indicate that there is no evidence supporting the idea that inflation is generally harmful to growth. 


\section{REFERENCES}

Andres, J and S. Hernando (1997), "Does Inflation Harm Economic Growth? Evidence for the OECD”, NBER Working Paper No. w6062.

Arellano, M. and S. Bond (1991), "Some Tests of Specification for Panel Data: Monte Carlo Evidence and an Application to Employment Equations", Review of Economic Studies, 58, 277-297.

Arellano, M. and Bover, O. (1995), “Another Look at the Instrumental Variable Estimation of Error-Components Models", Journal of Econometrics, 68, 29-52.

Barro, R. (1995), "Inflation and Economic Growth", Bank of England Bulletin, May, 166-176.

Barro R. and Sala-I-Martin, X. (1995), Economic Growth, McGraw Hill, Boston.

Blanchard, O. (1990), "Why Does Money Affect Output? A Survey", in Handbook of Monetary Economics, Vol II. Eds. Friedman, B. M. and Hahn, F. H. Amsterdam: North Holland.

Blundell, R. and S. Bond (1998), "Initial Conditions and Moment Restrictions in Dynamic Panel Data Models”, Journal of Econometrics, 87, 115-143.

Caselli, F., Esquivel, G. and F. Lefort (1996), "Reopening the Convergence Debate: A New Look at Cross-Country Growth Empirics", Journal of Economic Growth, September, 363-389.

Fischer, S. (1993), "The Role of Macroeconomic Factors in Growth", Journal of Monetary Economics, 32, 485-512.

Fischer, S. and F. Modigliani (1978), "Towards an Understanding of the Real Effects and Costs of Inflation", Weltwirtschaftliches Archiv, 114, 810832.

Hsiao, C. (1986), Analysis of Panel Data, Cambridge: Cambridge University Press.

IMF (1996), International Financial Statistics (IFS), Washington DC.

Islam, N. (1995), “Growth Empirics: A Panel Data Approach", Quarterly Journal of Economics, Vol. 110, November (4), 1127-1170.

Knight, M., Loayza, N. and Villaneuva, D. (1993), “Testing the Neoclassical 
Growth Model”, IMF Staff Papers, 40, 512-541.

Levine, R. and D. Renelt (1992), "Sensitivity Analysis of Cross Section Growth Regressions", American Economic Review, 82, 942-962.

Mankiw, N G., Romer, D. and D N. Weil (1992), "A Contribution to the Empirics of Economic Growth", Quarterly Journal of Economics, Vol. 107, May (2), 407-437.

Miller, M. and P. Weller (1991), "Exchange Rate Bands and Price Inertia", Economic Journal, 100, 1380-1399.

Temple, J. (1999), "The New Growth Evidence", Journal of Economic Literature, 37, 112-156.

Wansbeek, T. and A. Kapteyn (1989), "Estimation of the Error Components Model with Incomplete Panels", Journal of Econometrics, 43, 341-36. 
Table 1. Inflation and growth, fixed effects regressions, Samples A and B; $t$-statistics in parentheses.

\begin{tabular}{|c|c|c|c|c|c|c|}
\hline $\begin{array}{l}\text { Period/ } \\
\text { Sample }\end{array}$ & inflation $_{\text {it }}$ & $R^{2}$ & $F$ & $s d\left(v_{i}\right)$ & $s d\left(v_{i t}\right)$ & $\begin{array}{c}N / \\
\Sigma N x T_{i}\end{array}$ \\
\hline $\begin{array}{c}1960-1995 \\
\text { A }\end{array}$ & $\begin{array}{c}-0.00105^{* * *} \\
(-4.167)\end{array}$ & 0.08 & 6.36 & 2.29 & 4.96 & $\begin{array}{l}115 / \\
2874\end{array}$ \\
\hline $\begin{array}{c}1960-1995 \\
\text { B }\end{array}$ & $\begin{array}{c}-0.0235^{* * *} \\
(-4.60)\end{array}$ & 0.08 & 5.83 & 1.84 & 4.83 & $\begin{array}{l}97 / \\
2463\end{array}$ \\
\hline $\begin{array}{c}1960-1964 \\
\text { A }\end{array}$ & $\begin{array}{l}0.00007 \\
(-0.001)\end{array}$ & 0.000 & 0.00 & 2.85 & 3.83 & $\begin{array}{l}44 / \\
195\end{array}$ \\
\hline $\begin{array}{c}1960-1964 \\
\text { B }\end{array}$ & $\begin{array}{l}0.0262 \\
(0.364)\end{array}$ & 0.001 & 0.1 & 2.91 & 3.65 & $\begin{array}{l}40 / \\
180\end{array}$ \\
\hline $\begin{array}{c}1965-1969 \\
\text { A }\end{array}$ & $\begin{array}{l}0.0069 \\
(0.186)\end{array}$ & 0.000 & 0.03 & 3.36 & 3.72 & $\begin{array}{c}66 \\
/ 292\end{array}$ \\
\hline $\begin{array}{c}1965-1969 \\
\text { B }\end{array}$ & $\begin{array}{l}-0.0510 \\
(-1.207)\end{array}$ & 0.007 & 1.5 & 3.15 & 3.58 & $\begin{array}{l}56 / \\
249\end{array}$ \\
\hline $\begin{array}{c}1970-1974 \\
\text { A }\end{array}$ & $\begin{array}{l}-0.0165 \\
(-1.472)\end{array}$ & 0.007 & 2.2 & 3.19 & 5.28 & $\begin{array}{l}85 / \\
396\end{array}$ \\
\hline $\begin{array}{c}1970-1974 \\
\text { B }\end{array}$ & $\begin{array}{l}-0.0159 \\
(-1.341)\end{array}$ & 0.007 & 1.8 & 3.12 & 5.49 & $\begin{array}{l}72 / \\
335\end{array}$ \\
\hline $\begin{array}{c}1975-1979 \\
\text { A }\end{array}$ & $\begin{array}{c}-0.0378^{* * *} \\
(-2.804)\end{array}$ & 0.021 & 7.8 & 3.76 & 5.64 & $\begin{array}{c}100 / \\
467\end{array}$ \\
\hline $\begin{array}{c}1975-1979 \\
\text { B }\end{array}$ & $\begin{array}{c}-0.0557^{* * *} \\
(-3.308)\end{array}$ & 0.034 & 10.9 & 3.30 & 5.43 & $\begin{array}{l}85 / \\
395\end{array}$ \\
\hline $\begin{array}{c}1980-1984 \\
\text { A }\end{array}$ & $\begin{array}{l}-0.0004 \\
(-0.085)\end{array}$ & 0.000 & 0.01 & 3.45 & 5.96 & $\begin{array}{c}109 / \\
515\end{array}$ \\
\hline $\begin{array}{c}1980-1984 \\
\text { B }\end{array}$ & $\begin{array}{l}-0.0369^{*} \\
(-1.629)\end{array}$ & 0.008 & 2.65 & 3.33 & 6.01 & $\begin{array}{l}92 / \\
436\end{array}$ \\
\hline $\begin{array}{c}1985-1989 \\
\text { A }\end{array}$ & $\begin{array}{c}-0.0008^{* * *} \\
(-2.632)\end{array}$ & 0.016 & 6.9 & 3.06 & 4.22 & $\begin{array}{c}110 / \\
529\end{array}$ \\
\hline $\begin{array}{c}1985-1989 \\
\text { B }\end{array}$ & $\begin{array}{l}0.0015 \\
(0.108)\end{array}$ & 0.007 & 0.01 & 2.93 & 4.25 & $\begin{array}{l}94 / \\
453\end{array}$ \\
\hline $\begin{array}{c}1990-1995 \\
\text { A }\end{array}$ & $\begin{array}{c}-0.0013^{* * *} \\
(-3.418)\end{array}$ & 0.030 & 11.6 & 3.15 & 3.73 & $\begin{array}{c}106 / \\
480\end{array}$ \\
\hline $\begin{array}{c}1990-1995 \\
\text { B }\end{array}$ & $\begin{array}{c}-0.1077^{* * *} \\
(-4.779)\end{array}$ & 0.064 & 22.8 & 2.86 & 3.38 & $\begin{array}{l}92 / \\
425\end{array}$ \\
\hline
\end{tabular}

NOTES

i) ${ }^{* * *}$ and ${ }^{* * *}$., denotes significance at 10,5 and 1 percent level. All specifications include budget deficit and year dummies.

ii) The results of the fixed effects model estimated, as proposed by Wansbeek and Kapteyn (1989), are almost identical to the estimates obtained from individual fixed effects model including time dummies. For the entire period, we obtained an estimate of -0.00105 with a t-ratio of -4.279 , which is quite close to the coefficients when year dummies are included.

iii) We tested for attrition by including a dummy variable taking the value 1 when the preceding year is not missing and zero otherwise. This variable turned out to be insignificant, which we interpret as evidence that the attrition problem is not decisive for our results.

iv) We also check for panel specific auto-correlation. Results are essentially the same. Contrary to the properties of our sample, one should only employ an autoregressive model when the time dimension is larger than the cross-section dimension. Running an autoregressive model in a complete panel of 15 countries in 36 years yields essentially the same results. 
Table 2. Dynamic panel data estimations of inflation and growth, one-step GMM estimators, Samples A and B; $t$-statistics based on robust standard errors in parentheses. Note: The coefficient for the lagged dependent variable is not reported.

\begin{tabular}{|c|c|c|c|c|c|}
\hline Period/Tests & $\begin{array}{c}\text { GMMY }_{Y} \\
\text { inflation }_{\text {it }}\end{array}$ & $\begin{array}{l}G^{G M M} M_{Y, X} \\
\text { inflation }_{\text {it }}\end{array}$ & $\begin{array}{c}G M M Y \\
\text { inflation }_{\text {it-1 }}\end{array}$ & $\begin{array}{c}G^{G M} M_{Y, X} \\
\text { inflation } \\
\text { it-1 }\end{array}$ & $N / \Sigma N x T_{i}$ \\
\hline : 1965-69 & $0.008(0.17)$ & $0.004(0.08)$ & $-0.031(-0.42)$ & $-0.015(-0.20)$ & $60 / 248$ \\
\hline $\mathrm{AR}(1) / \mathrm{AR}(2)$ & $-3.19^{* *} / 0.12$ & $-2.98^{* *} /-0.05$ & $-3.24^{* *} / 0.16$ & $-3.06^{* *} /-0.04$ & \\
\hline Sargan Test & 12.13 & 20.57 & 12.72 & 18.22 & \\
\hline : 1965-69 & $-0.041(-1.57)$ & $-0.053^{*}(-1.73)$ & $-0.067(-0.74)$ & $-0.024(-0.39)$ & $50 / 213$ \\
\hline $\mathrm{AR}(1) / \mathrm{AR}(2)$ & $-3.31^{* *} / 0.05$ & $-3.31^{* *} / 0.01$ & $-3.32^{* *} / 0.12$ & $-3.36^{* *} / 0.01$ & \\
\hline Sargan & 9.01 & 25.89 & 11.00 & $29.94^{*}$ & \\
\hline : 1970-74 & $-0.031^{*}(-1.81)$ & $-0.025^{* *}(-2.03)$ & 0.009 & $0.001(0.10)$ & $80 / 358$ \\
\hline $\mathrm{AR}(1) / \mathrm{AR}(2)$ & $-3.62^{* *} /-1.23$ & $-3.36^{* *} /-1.35$ & $-3.63^{* *} /-1.25$ & $-3.36^{* *} /-1.36$ & \\
\hline Sarg & 9.78 & $28.01^{*}$ & 9.88 & $28.88^{*}$ & \\
\hline : 1970-74 & $-0.027^{*}(-1.84)$ & $-0.023^{* *}(-2.13)$ & $0.009(-0.50)$ & $-0.003(-0.21)$ & $66 / 298$ \\
\hline $\mathrm{AR}(1) / \mathrm{AR}(2)$ & $-3.00^{* *} /-1.20$ & $-2.80^{* *} /-1.28$ & $-3.01^{* *} /-1.20$ & $-2.83^{* *} /-1.29$ & \\
\hline & 7.96 & 22.82 & 7.96 & 21.83 & \\
\hline$: 197$ & $.023^{* * *}(-2.32)$ & $26^{* * *}(-3.70)$ & 0.015 & $-0.008(-0.38)$ & $96 / 435$ \\
\hline /AR(2) & $-4.09^{* *} /-1.18$ & $-4.02^{* *} /-1.20$ & $-4.12^{* *} /-1.12$ & $-3.98 * * /-1.17$ & \\
\hline Sarg & 15.34 & 24.28 & 15.13 & 26.89 & \\
\hline 197 & $-0.016(-0.55)$ & $-0.028^{* * *}(-3$. & $-0.015(-0.43)$ & $-0.030^{* * *}(-2.56)$ & $81 / 364$ \\
\hline $\mathrm{AR}($ & $-3.45^{* *} /-1.33$ & $-3.42^{* *} /-1.34$ & $-3.38^{* *} /-1.34$ & $-3.18^{* *} /-1.39$ & \\
\hline & 13.93 & 20.39 & 13.91 & 22.75 & \\
\hline$: 19$ & 804 & -0.003 & 0.013 & 0.0 & $105 / 4$ \\
\hline $\mathrm{AR}$ & $-4.81^{* *} /-0$ & $-4.79 * * /-0$. & $-4.75^{* *} /-0.78$ & $-4.79^{* *} /-($ & \\
\hline & & & 6.82 & & \\
\hline$: 198$ & $070^{* *}(-2.09)$ & $-0.062 *(-1.8$ & $0.078(1$ & $0.072(1.43)$ & $89 / 421$ \\
\hline $\mathrm{AR}$ & $-4.18^{* *} /-0.33$ & $-4.10^{* *} /-0.49$ & $-4.30^{* *} /-0.16$ & $-4.33^{* *} /-0.21$ & \\
\hline & & & 7.20 & & \\
\hline : 19 & 000 & -0.00 & 0.00 & -0.000 & $108 / 51$ \\
\hline & -3.0 & $-3.06^{\circ}$ & $-3.02 *$ & $-3.01^{*}$ & \\
\hline & & & & & \\
\hline 3: 198 & 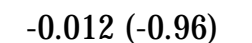 & -0.010 & $0.030(1.33)$ & $0.019(1.35)$ & $93 / 447$ \\
\hline $\mathrm{AR}($ & $-2.69^{* *}$ & $-2.67^{*}$ & $-2.76^{*} / 0.30$ & $-2.73^{\prime}$ & \\
\hline & 9.8 & & & & \\
\hline A: 19 & $.000 s$ & -0.001 & $0.001^{* * *}(4.04)$ & 0.000 & $106 / 476$ \\
\hline $\mathrm{AR}$ & $-4.53^{* *} /$ & $-4.42^{* *} / 0.46$ & $-4.43^{* *} / 0.73$ & $-4.31^{* *} / 0.70$ & \\
\hline & & & & & \\
\hline : 1990-9 & $097^{* *}(-2.04)$ & $-0.082 *(-1$. & $0.023(0.97)$ & $0.019(0.91)$ & $91 / 424$ \\
\hline & $-3.98^{* *} /-0.79$ & $-3.95^{* *} /-0.79$ & $-3.99^{* *} / 0.88$ & $-3.94^{* *} / 0.85$ & \\
\hline Sargan Test & 4.25 & 26.69 & 4.49 & 20.72 & \\
\hline
\end{tabular}

NOTES

i) ${ }^{*}{ }^{* *}$ and ${ }^{* * *}$., denotes significance at 10, 5 and 1 percent level. Results are robust for including budget deficit in the estimations.

ii) All models include yearly dummies. The GMM-y estimator uses instruments for the lagged dependent variable. The GMM-y,x estimator uses instruments for the lagged dependent variable as well as instruments for the inflation rate.

iii) $\mathrm{AR}(1)$ is the test-statistica for first-order serial correlation in the first differenced residuals. $\operatorname{AR}(2)$ is the test-statistica for second order serial correlation in the differenced residuals. The Sargan Test is the test-statistica for overidentifying restrictions. 
Figure 1. Inflation and GDP change: Sample $B$ averages, 1960-95

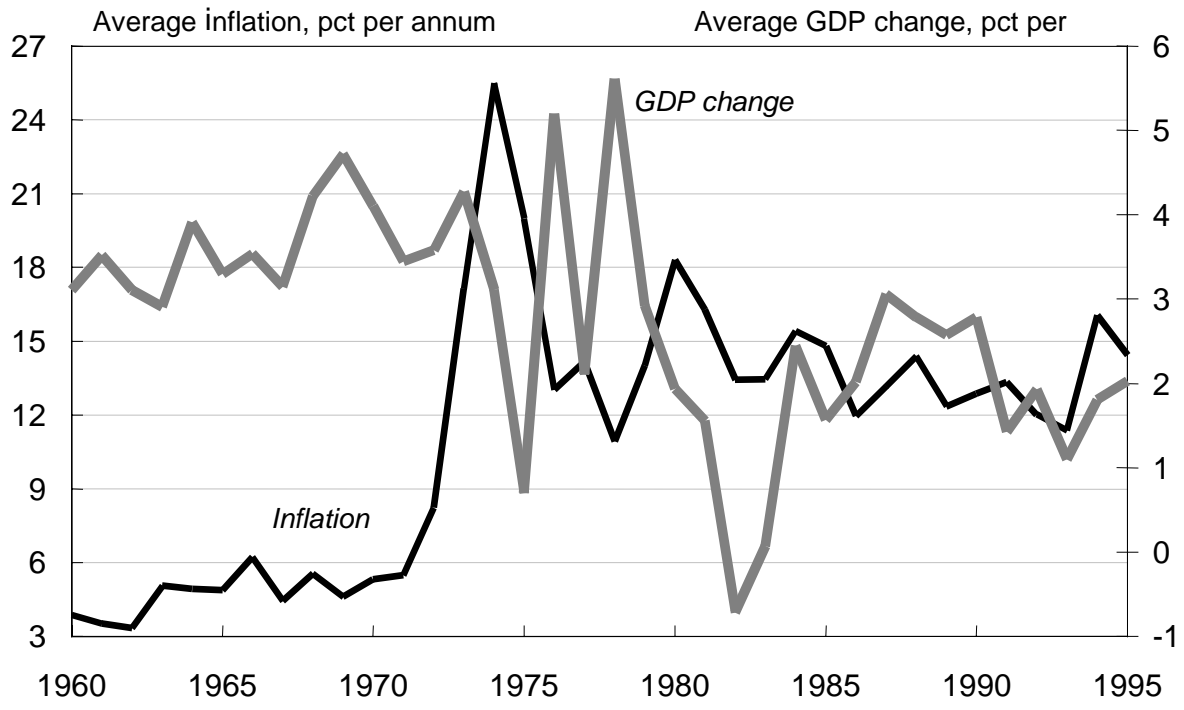

Figure 2. Inflation \& GDP change: Averages for the sample; inflation $<10$ \& GDP-change $>0$

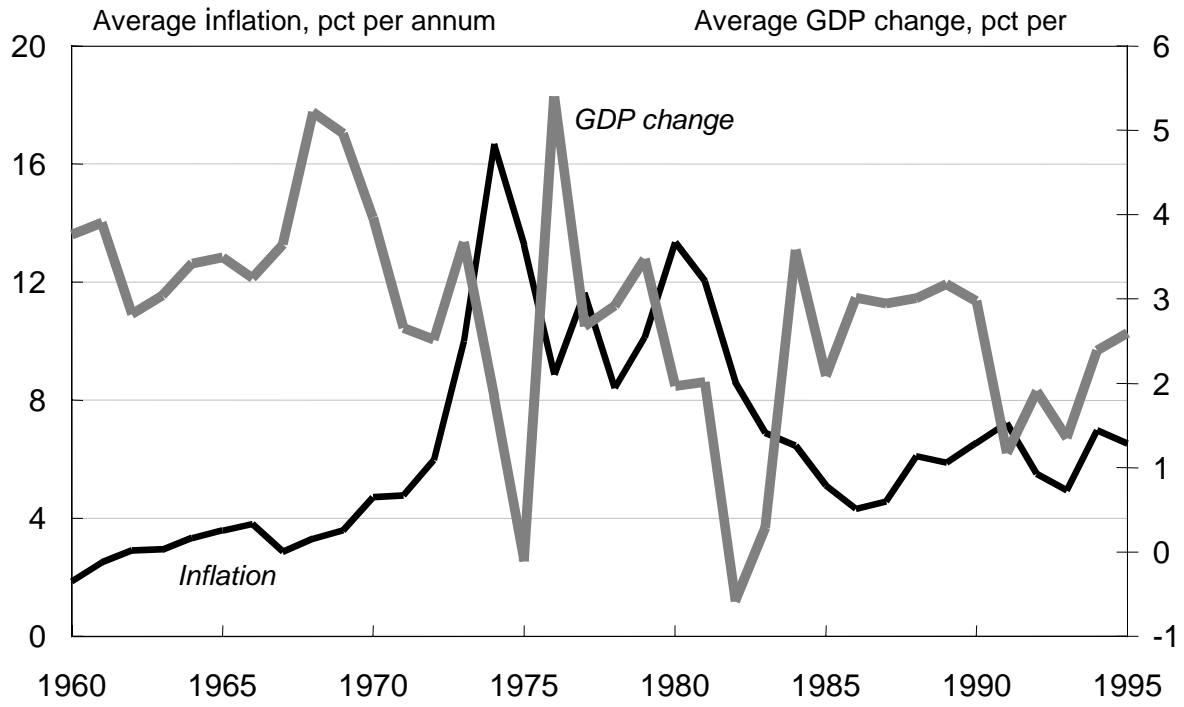


Figure 3. Average growth and average inflation, 1960-95

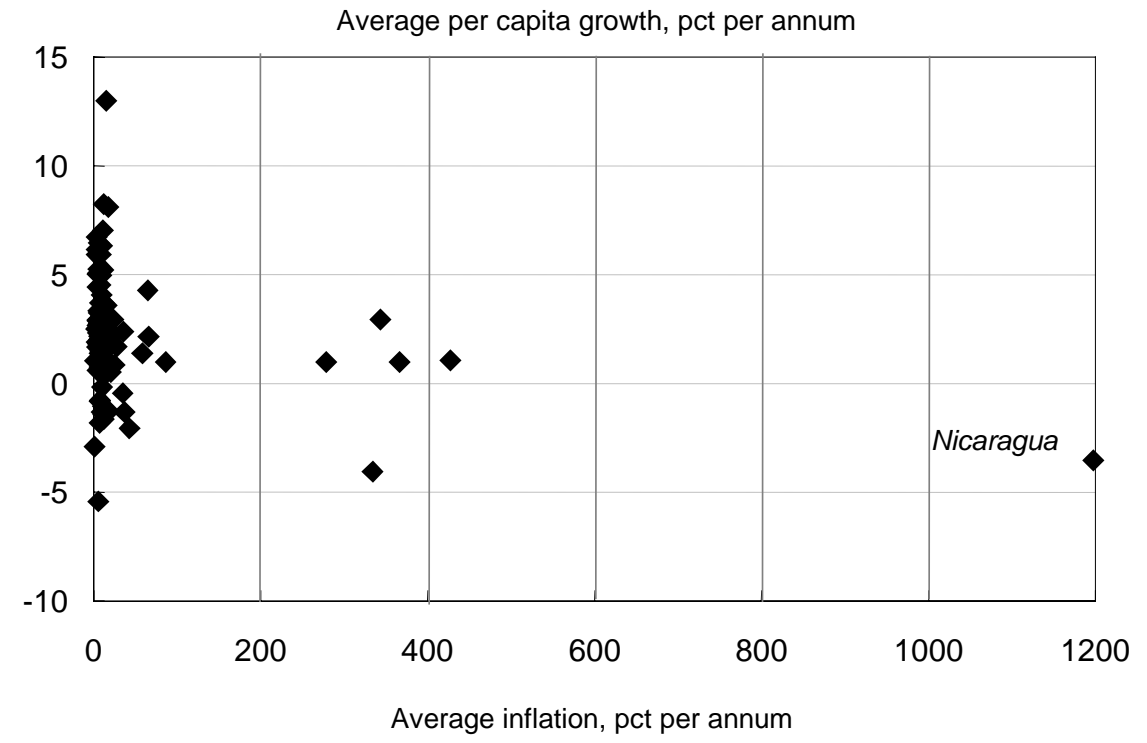

Figure 4. Average growth and average inflation, 1960-65

\section{Sample B}

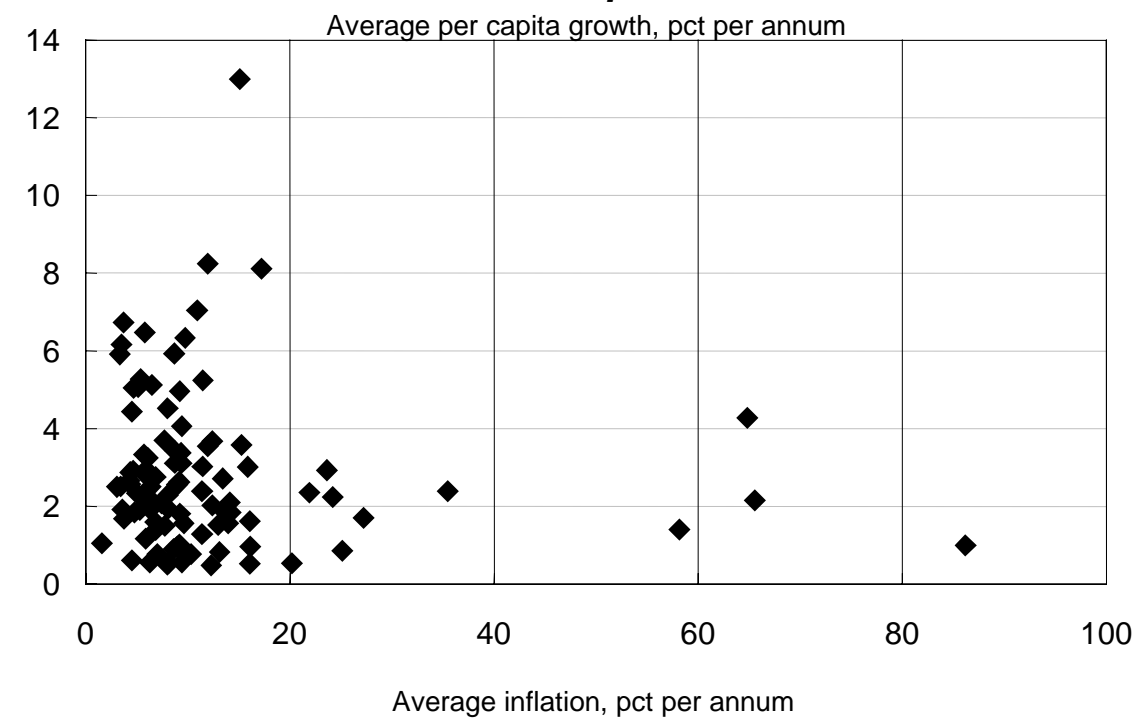


Figure 5. Average growth and average inflation, 1960-95 OECD

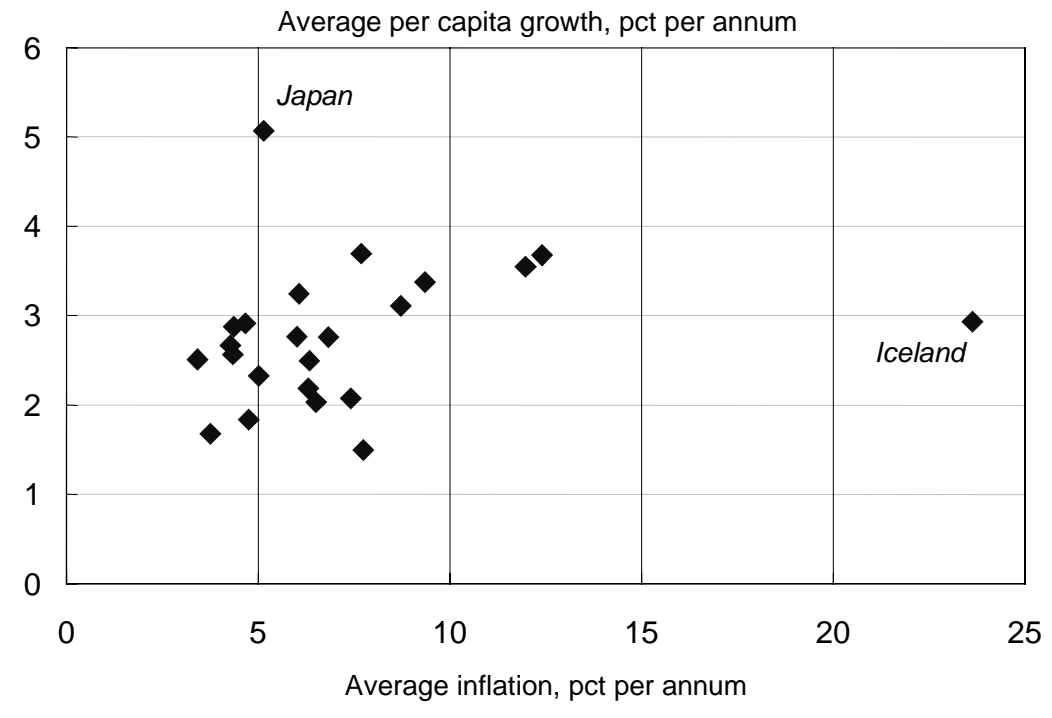




\section{Appendix :}

Table A1. Inflation and growth. Averages are calculated only with respect to years where we record both inflation and growth.

\begin{tabular}{|c|c|c|c|c|c|c|c|}
\hline Country & $T_{i}$ & $\begin{array}{l}\text { Average } \\
\text { inflation }\end{array}$ & $\begin{array}{c}s d \\
\text { (inflation) }\end{array}$ & $\begin{array}{c}C V \\
\text { (inflation) }\end{array}$ & $\begin{array}{c}\text { Maximum } \\
\text { inflation }\end{array}$ & $\begin{array}{l}\text { Average } \\
\text { growth }\end{array}$ & $\begin{array}{c}s d \\
\text { (growth) }\end{array}$ \\
\hline Algeria & 13 & 8.7 & 4.28 & 0.49 & 17.2 & 3.4 & 6.04 \\
\hline Antigua & 8 & 8.0 & 6.75 & 0.84 & 19 & 4.5 & 10.30 \\
\hline Argentina & 35 & 278.3 & 633.52 & 2.28 & 3079.8 & 1.0 & 5.20 \\
\hline Australia & 36 & 6.3 & 4.13 & 0.66 & 15.1 & 2.2 & 2.20 \\
\hline Austria & 34 & 4.4 & 2.05 & 0.46 & 9.5 & 2.9 & 1.92 \\
\hline Bahrain & 19 & 4.5 & 7.25 & 1.61 & 22.5 & 0.6 & 7.68 \\
\hline Bangladesh & 21 & 11.4 & 11.14 & 0.98 & 54.8 & 2.4 & 2.76 \\
\hline Barbados & 25 & 9.4 & 7.77 & 0.83 & 38.9 & 3.1 & 5.29 \\
\hline Belgium & 34 & 4.7 & 3.06 & 0.66 & 12.8 & 2.9 & 2.15 \\
\hline Belize & 14 & 3.6 & 1.50 & 0.60 & 11.2 & 1.9 & 4.98 \\
\hline Bhutan & 10 & 9.2 & 4.04 & 0.44 & 18 & 5.0 & 4.30 \\
\hline Bolivia & 33 & 427.3 & 2045.18 & 4.79 & 11749.6 & 1.1 & 3.75 \\
\hline Botswana & 20 & 11.5 & 2.35 & 0.20 & 16.4 & 5.2 & 6.23 \\
\hline Brazil & 30 & 343.7 & 676.58 & 1.97 & 2937.8 & 2.9 & 5.46 \\
\hline Burkina F. & 22 & 5.9 & 8.56 & 1.46 & 30.0 & 1.2 & 5.50 \\
\hline Burundi & 22 & 9.6 & 8.04 & 0.84 & $36 . .5$ & 1.6 & 4.94 \\
\hline Cameron & 21 & 9.2 & 5.04 & 0.54 & 17.2 & 1.8 & 5.32 \\
\hline Canada & 36 & 5.0 & 3.30 & 0.66 & 12.5 & 2.3 & 2.70 \\
\hline Chad & 4 & 1.6 & 14.57 & 9.10 & 20.3 & 1.0 & 14.96 \\
\hline Chile & 35 & 65.5 & 115.43 & 1.76 & 504.7 & 2.2 & 5.58 \\
\hline China & 8 & 12 & 7.99 & 0.67 & 24.2 & 8.2 & 3.92 \\
\hline Colombia & 27 & 21.9 & 6.46 & 0.29 & 33.1 & 2.4 & 1.71 \\
\hline Costa Rica & 34 & 14.1 & 16.73 & 1.18 & 90.1 & 2.1 & 3.95 \\
\hline Cyprus & 33 & 4.7 & 3.65 & 0.78 & 14.1 & 5.0 & 8.38 \\
\hline Denmark & 36 & 6.3 & 3.49 & 0.55 & 15.3 & 2.5 & 2.29 \\
\hline Dominica & 17 & 9.4 & 23.69 & 2.52 & 86.5 & 4.1 & 7.24 \\
\hline Dominican Rep. & 32 & 14.2 & 16.25 & 1.14 & 59.4 & 1.8 & 4.99 \\
\hline Ecuador & 30 & 24.2 & 19.03 & 0.79 & 75.6 & 2.2 & 4.89 \\
\hline Egypt & 13 & 15.9 & 4.82 & 0.30 & 23.9 & 3.0 & 2.54 \\
\hline Ethiopia & 26 & 7.4 & 10.03 & 1.36 & 35.7 & -0.8 & 5.82 \\
\hline Fiji & 10 & 6.8 & 3.00 & 0.44 & 11.8 & 1.4 & 4.70 \\
\hline Finland & 35 & 6.9 & 4.38 & 0.63 & 17.8 & 2.8 & 3.34 \\
\hline France & 36 & 6.0 & 3.73 & 0.62 & 13.5 & 2.8 & 1.88 \\
\hline Gambia & 24 & 13.0 & 11.16 & 0.86 & 56.6 & 1.5 & 12.56 \\
\hline Germany & 34 & 3.5 & 1.89 & 0.50 & 7.0 & 2.5 & 2.15 \\
\hline Ghana & 29 & 35.8 & 34.01 & 0.98 & 122.9 & -0.4 & 5.16 \\
\hline Greece & 35 & 12 & 8.37 & 0.70 & 26.9 & 3.5 & 3.72 \\
\hline Grenada & 16 & 8.7 & 7.95 & 0.92 & 21.5 & 5.9 & 10.35 \\
\hline Guatemala & 35 & 9.2 & 10.47 & 1.14 & 41.2 & 1.0 & 2.98 \\
\hline Guyana & 32 & 9.8 & 9.64 & 0.99 & 39.9 & -0.2 & 7.24 \\
\hline Haiti & 29 & 10.7 & 10.46 & 0.97 & 42.6 & -1.0 & 4.86 \\
\hline Honduras & 36 & 8.0 & 8.12 & 1.02 & 34 & 0.5 & 3.51 \\
\hline Iceland & 34 & 24.2 & 20.17 & 0.75 & 84.2 & 2.9 & 4.28 \\
\hline India & 33 & 8.1 & 6.04 & 0.75 & 28.6 & 1.9 & 3.40 \\
\hline Indonesian & 36 & 15.3 & 8.50 & 0.66 & 45.9 & 3.6 & 2.17 \\
\hline Iran & 30 & 14 & 9.56 & 0.68 & 31.5 & 1.6 & 10.06 \\
\hline Ireland & 36 & 7.7 & 5.96 & 0.76 & 20.9 & 3.7 & 2.24 \\
\hline Israel & 26 & 64.8 & 91.30 & 1.41 & 373.8 & 4.3 & 12.20 \\
\hline Italy & 34 & 8.7 & 5.81 & 0.65 & 21.2 & 3.1 & 2.36 \\
\hline Ivory coast & 5 & 16.1 & 6.94 & 0.43 & 27.4 & 1.6 & 2.95 \\
\hline Jamaica & 33 & 16.1 & 15.89 & 0.98 & 77.3 & 1.0 & 4.10 \\
\hline Japan & 35 & 5.1 & 4.32 & 0.80 & 23.1 & 5.1 & 3.44 \\
\hline Jordan & 25 & 8.6 & 6.44 & 0.81 & 25.7 & 0.9 & 7.32 \\
\hline Kenya & 28 & 13.1 & 9.97 & 0.76 & 45.8 & 0.8 & 3.77 \\
\hline Korea & 28 & 10.9 & 7.90 & 0.74 & 28.7 & 7.0 & 3.32 \\
\hline Liberia & 23 & 6.9 & 5.81 & 0.84 & 19.6 & -1.8 & 5.75 \\
\hline Libya & 14 & 5.8 & 8.96 & 1.55 & 29.4 & 6.5 & 9.69 \\
\hline
\end{tabular}




\begin{tabular}{|c|c|c|c|c|c|c|c|}
\hline Luxembourg & 35 & 4.5 & 2.95 & 0.68 & 10.7 & 2.7 & 3.14 \\
\hline Madagascar & 30 & 12.1 & 9.75 & 0.81 & 38.9 & -1.6 & 5.29 \\
\hline Malawi & 14 & 18.1 & 8.36 & 0.46 & 34.7 & 1.3 & 5.46 \\
\hline Malaysia & 24 & 4.5 & 3.68 & 0.81 & 17.3 & 4.4 & 2.96 \\
\hline Mali & 3 & 0.8 & 0.96 & 1.25 & 1.8 & -3.0 & 10.34 \\
\hline Malta & 32 & 3.5 & 3.87 & 1.10 & 15.7 & 6.2 & 5.50 \\
\hline Mauritius & 30 & 9.1 & 8.75 & 0.96 & 42 & 2.6 & 6.02 \\
\hline Mexico & 36 & 27.2 & 33.87 & 1.24 & 131.8 & 1.7 & 3.45 \\
\hline Morocco & 30 & 6.3 & 3.86 & 0.52 & 17.6 & 1.9 & 4.76 \\
\hline Myanmar & 27 & 12.4 & 12.30 & 0.91 & 19.8 & 2.0 & 5.48 \\
\hline Nepal & 30 & 8.9 & 5.95 & 0.67 & 19.8 & 1.0 & 3.22 \\
\hline Netherlands & 36 & 4.3 & 2.74 & 0.63 & 10.3 & 2.6 & 2.38 \\
\hline New Zealand & 36 & 7.7 & 5.46 & 0.69 & 17.1 & 1.5 & 2.41 \\
\hline Nicaragua & 23 & 1197.7 & 3210.08 & 1.97 & 10205.0 & -3.5 & 9.11 \\
\hline Niger & 15 & 9.7 & 8.13 & 0.79 & 23.5 & -1.3 & 9.10 \\
\hline Nigeria & 21 & 25.1 & 18.15 & 0.72 & 57.2 & 0.9 & 7.81 \\
\hline Norway & 36 & 6.1 & 3.29 & 0.54 & 13.7 & 3.2 & 1.70 \\
\hline Pakistan & 23 & 10.4 & 5.86 & 0.56 & 26.7 & 2.6 & 1.57 \\
\hline Panama & 35 & 3.1 & 3.73 & 1.22 & 16.3 & 2.5 & 4.26 \\
\hline Papua & 20 & 7.2 & 4.36 & 0.60 & 23.2 & 0.8 & 4.94 \\
\hline Paraguay & 36 & 13.6 & 10.26 & 0.76 & 38.2 & 1.9 & 3.28 \\
\hline Peru & 36 & 366.8 & 1345.84 & 3.67 & 7481.7 & 1.0 & 5.51 \\
\hline Philippines & 36 & 11.4 & 9.62 & 0.84 & 50.3 & 1.3 & 3.25 \\
\hline Portugal & 35 & 12.4 & 7.69 & 0.50 & 29.3 & 3.7 & 4.37 \\
\hline Romania & 14 & 62.1 & 51.05 & 0.24 & 255.2 & -1.3 & 8.86 \\
\hline Rwanda & 26 & 8.1 & 8.49 & 1.05 & 31.1 & 0.5 & 3.88 \\
\hline Saudi Arabia & 26 & 5.3 & 10.52 & 1.88 & 34.6 & 1.9 & 7.10 \\
\hline Senegal & 13 & 7.2 & 6.24 & 0.86 & 17.4 & -0.8 & 6.36 \\
\hline Seychelles Is. & 15 & 5.7 & 5.44 & 0.95 & 14.9 & 3.3 & 6.17 \\
\hline Sierra Leone & 23 & 42.7 & 42.02 & 0.98 & 181.6 & -2.1 & 4.92 \\
\hline Singapore & 35 & 3.7 & 5.77 & 1.52 & 26.2 & 6.7 & 3.94 \\
\hline Solomon Is. & 7 & 11.5 & 3.24 & 0.28 & 16.4 & -1.4 & 5.46 \\
\hline South Africa & 36 & 9.4 & 5.27 & 0.56 & 18.6 & 0.6 & 3.02 \\
\hline Spain & 36 & 9.3 & 5.44 & 0.58 & 24.5 & 3.4 & 2.90 \\
\hline Sri Lanka & 32 & 8.0 & 6.62 & 0.83 & 26.1 & 2.3 & 4.30 \\
\hline St Kitts & 13 & 3.3 & 2.80 & 0.84 & 10.5 & 5.9 & 11.84 \\
\hline St Lucia & 14 & 5.9 & 5.51 & 0.93 & 19.5 & 3.0 & 6.73 \\
\hline St Vincent & 17 & 6.5 & 4.99 & 0.77 & 17.2 & 5.1 & 6.97 \\
\hline Suriname & 20 & 15.1 & 13.32 & 0.86 & 53.4 & 13.0 & 8.79 \\
\hline Swaziland & 17 & 13.5 & 3.93 & 0.29 & 20.5 & 2.7 & 5.39 \\
\hline Sweden & 36 & 6.5 & 3.19 & 0.49 & 13.7 & 2.0 & 2.11 \\
\hline Switzerland & 36 & 3.7 & 2.20 & 0.59 & 9.8 & 1.7 & 2.40 \\
\hline Syria & 34 & 11.4 & 12.44 & 1.09 & 59.5 & 3.0 & 7.98 \\
\hline Tanzania & 29 & 20.2 & 10.33 & 0.49 & 36.1 & 0.5 & 2.08 \\
\hline Thailand & 35 & 5.4 & 5.61 & 0.93 & 24.3 & 5.3 & 2.75 \\
\hline Togo & 20 & 7.1 & 7.53 & 1.06 & 22.5 & -0.8 & 3.72 \\
\hline Tonga & 19 & 9.7 & 6.71 & 0.68 & 22.4 & 6.3 & 12.19 \\
\hline Trinidad & 27 & 10.3 & 4.98 & 0.48 & 22 & 0.8 & 4.92 \\
\hline Tunisia & 11 & 6.8 & 1.59 & 0.24 & 8.9 & 1.6 & 2.77 \\
\hline Turkey & 35 & 35.5 & 15.63 & 0.22 & 110.2 & 2.4 & 4.05 \\
\hline Uganda & 13 & 86.2 & 72.10 & 0.85 & 200 & 1.0 & 3.61 \\
\hline UK & 35 & 7.4 & 5.39 & 0.73 & 24.1 & 2.1 & 2.23 \\
\hline Uruguay & 36 & 58.2 & 27.93 & 0.48 & 125.3 & 1.4 & 3.85 \\
\hline USA & 36 & 4.7 & 3.11 & 0.65 & 13.4 & 1.8 & 2.12 \\
\hline Vanuatu & 10 & 6.3 & 4.11 & 0.65 & 16 & 0.6 & 5.88 \\
\hline Venezuela & 36 & 16.1 & 19.90 & 1.24 & 84.5 & 0.5 & 4.02 \\
\hline Zaire & 22 & 334.3 & 958.86 & 2.87 & 4129.2 & -4.0 & 7.17 \\
\hline Zimbabwe & 19 & 12.3 & 5.76 & 0.40 & 23.3 & 0.5 & 5.74 \\
\hline
\end{tabular}


Table A2. Sample statistics.

\begin{tabular}{lccccc}
\hline \multicolumn{1}{c}{ Variable } & Obs & Average & Std & Min & Max \\
\hline & Sample A: 115 countries & & & \\
\hline growth & 2874 & 2.09 & 5.42 & -32.8 & 47.83 \\
inflation & 2874 & 39.69 & 391.66 & -36.7 & 11749 \\
annual SD of quarterly inflation & 2874 & 11.29 & 156.10 & 0.00 & 6168.78 \\
budget deficit & 2389 & 3.69 & 5.70 & -22.63 & 68.46 \\
\hline \multicolumn{7}{l}{ Sample B: Sample A excluding countries with average inflation above 200 percent and } \\
& negative average growth. \\
growth & 2436 & 2.58 & 5.15 & -24.17 & 47.83 \\
inflation & 2436 & 12.31 & 23.73 & -36.7 & 504.70 \\
annual SD of quarterly inflation & 2436 & 3.08 & 7.65 & 0.00 & 151.47 \\
budget deficit & 2062 & 3.14 & 4.71 & -22.63 & 68.46 \\
\hline
\end{tabular}

